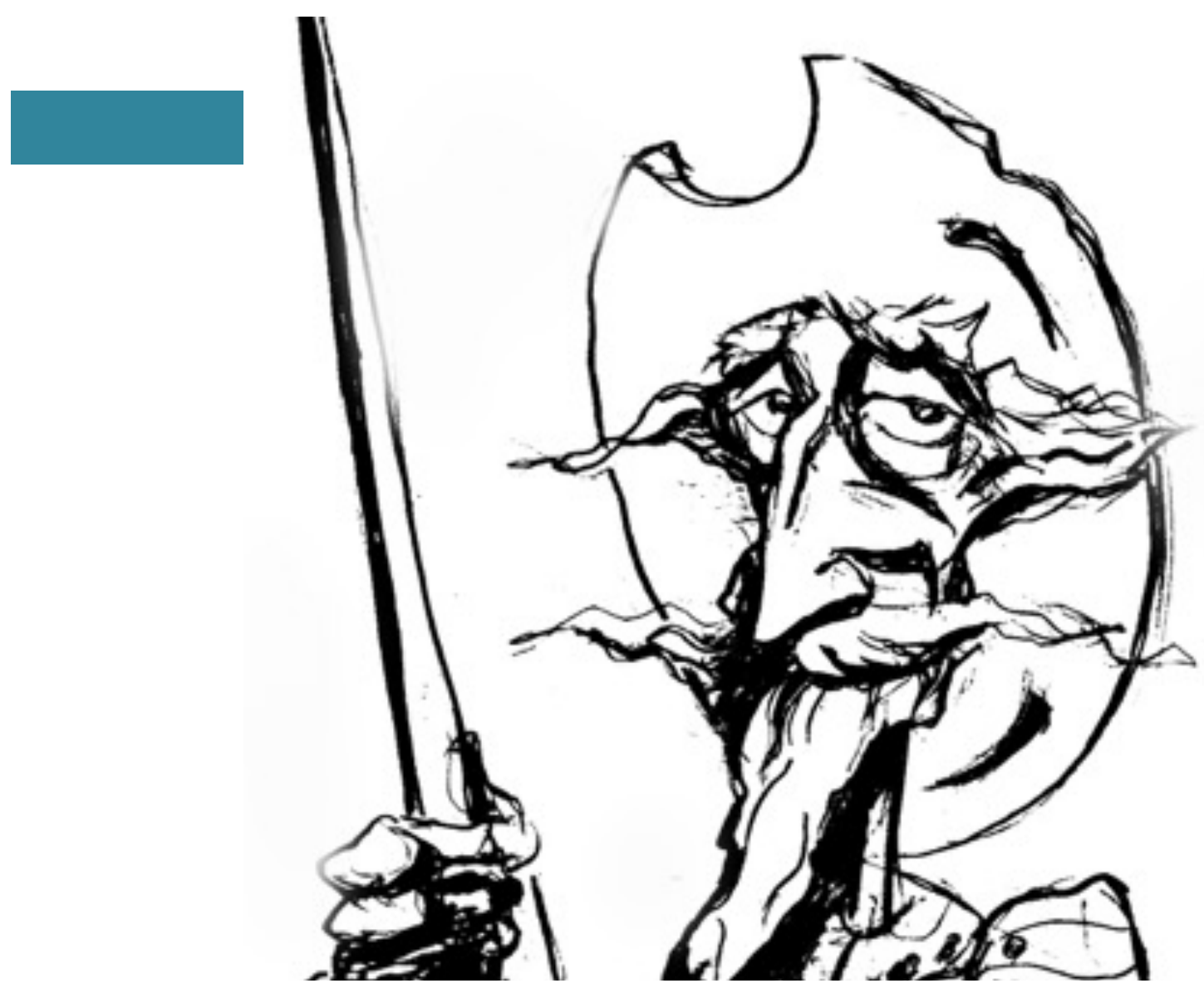

Las memorias del historiador.

Comentarios en torno a Una juventud en los años sesenta de Juan Carlos Garavaglia

[Luciano Alonso] 


\title{
Las memorias del historiador. Comentarios en torno a Una juventud en los años sesenta de Juan Carlos Garavaglia*
}

\author{
The memories of the historian. Notes about Una juventud en los años sesenta of \\ Juan Carlos Garavaglia
}

LUCIANO ALONSO

\section{Resumen}

El presente texto propone leer el libro Una juventud en los años sesenta de Juan Carlos Garavaglia, como una autobiografía política que da cuenta también de una educación sentimental. Se identifican un eje temático y un eje teórico-conceptual, para luego analizar el modo en el cual se escribió un texto en el cual se tocan la memoria y la historia. Finalmente, el ensayo propone que las memorias de Garavaglia invitan a la reflexión sobre el pasado reciente de Argentina.

\section{Palabras claves}

Memoria - Historia - Autobiografía - Educación Política - Educación Sentimental

\begin{abstract}
This text proposes to read Juan Carlos Garavaglia's book Una juventud en los años sesenta, as a political autobiography that realizes also of a sentimental education. There are identified a thematic axis and a theoretical-conceptual axis, then to analyze the way in which thetext contacts history and memory. Finally, these comments propose that Garavaglia's memories invite to the reflection on the recent past of Argentina.
\end{abstract}

\section{Keywords}

Memory - History - Autobiography - Political Education - Sentimental Education

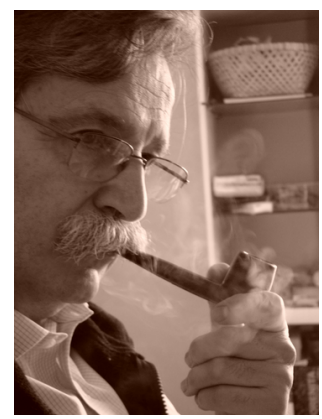

Recibido con pedido de publicación el 2 de octubre de 2017

Aceptado para su publicación el 31 de octubre de 2017

Versión definitiva recibida el 29 de diciembre de 2017

Luciano Alonso, Universidad Nacional del Litoral, Argentina; e-mail: 1pjalonso8@gmail.com / lalonso@fhuc.unl.edu.ar

* GARAVAGLIA, Juan Carlos Una juventud en los años sesenta, Prometeo, Buenos Aires, 2015, 208 pp.

Esta obra se publica bajo licencia Creative Commons. Atribución-NoComercial-CompartirIgual 4.0 Internacional

Alonso, Luciano "Las memorias del historiador. Comentarios en torno a Una juventud en los años sesenta de Juan Carlos Garavaglia", Prohistoria, Año XX, núm. 28, Homenaje a Juan Carlos Garavaglia, dic. 2017, pp. 207-216. 
1.

Pocas cuestiones tuvieron un grado de internacionalización e incremento de debates en el campo historiográfico y en vínculo con otras disciplinas académicas conexas, como la relación entre historia y memoria. Han sido ingentes las exploraciones y discusiones sobre las fuentes orales y la historia oral, sobre el estatuto del testigo, sobre las operaciones memoriales y su dimensión monumental, sobre la articulación que supondría la memoria histórica o por el contrario el oxímoron que se escondería en esa expresión. Esos desarrollos han sido coetáneos y estuvieron vinculados con lo que en Argentina recibe el nombre de "Historia Reciente", concebida mayormente como una tendencia historiográfica o campo de investigación que "refierea procesos históricos cuyas consecuencias directas conservan aun fuertes efectos sobreel presente, en particular en áreas muy sensibles, como el avasallamiento de losderechos humanos más elementales" y que en algunas universidades nacionales llega a reunir actualmente hasta una quinta parte de las tesis doctorales. ${ }^{1}$

De entre la multitud de trabajos dedicados al estudio de las memorias y a las variadas facetas de su relación con la historiografía, José Sazbón destacó dos actitudes antitéticas, que suponían no sólo diferentes posicionamientos respecto de la relación de los/las historiadores $/ \mathrm{as}^{2}$ con el mundo social, sino también enfoques diversos sobre lo que implica la propia labor académica. ${ }^{3}$ Por un lado, el derivado de la operación de fragmentación y anulación del pasado propio de la "galaxia Furet" que representara Pierre Nora, con una monumental obra marcada por la escisión entre memoria e historia. ${ }^{4} \mathrm{Su}$ premisa general sería la extinción de la conciencia histórica y la eliminación de la memoria como captación viva de una permanencia, para pasar a ser con un conjunto de curiosidades académicas, objetos de estudio claramente separados de la propia subjetividad del historiador, que realizaría su actividad académica con espíritu autocrítico y de manera voluntaria e individual. Por el otro, la opción diferencial que representara Raphael Samuel, ya que si bien éste compartía con Nora una preocupación por la exploración de las articulaciones entre memoria e historia, sus desarrollos partían de premisas, motivaciones y contextos de producción muy distintos, y a su vez se alejaban de la autocomplacencia cultural del historiador francés. En Samuel, la memoria aparecía como una reserva de sentido constantemente revisada y revisitada de la cual se podían extraer recursos emancipatorios, en tanto que la historia se presentaba no como una prerrogativa o invención del historiador individual sino como una forma social de conocimiento, de la cual participan archiveros, bibliotecarios, restauradores, indexadores, correctores de estilo, lectores de pruebas, coleccionistas, cronistas populares, operarios de las más variadas profesiones y un sinnúmero de agentes en procesos al mismo tiempo colaborativos y conflictivos. ${ }^{5}$

\footnotetext{
${ }^{1}$ FRANCO, Marina y LVOVICH, Daniel "Historia Reciente: apuntes sobre un campo de investigación en expansión", en Boletín del Instituto de Historia Argentina y Americana "Dr. Emilio Ravignani" núm. 47, 2017, entrecomillado de p. 191.

${ }^{2}$ Aunque soy consciente de la necesidad de generar discursos no sexistas que incorporen las variantes femeninas y masculinas en la enunciación, por motivos de facilidad de lectura en la mayor parte de los casos recurro a la forma de pluralización usual en la lengua castellana. Por ello, de aquí en adelante solicito a lectoras y lectores que recuerden que se trata de una opción asumida con una función meramente instrumental.

${ }^{3}$ SAZBÓN, José "Conciencia histórica y memoria electiva", en Nietzsche en Francia y otros estudios de historia intelectual, Universidad Nacional de Quilmes, Quilmes, 2009

${ }^{4}$ NORA, Pierre (dir.) Les lieux de mémoire, Gallimard, Paris, 1984-1992.

${ }^{5}$ SAMUEL, Raphael Teatros de la memoria. Pasado y presente de la cultura contemporánea, Prensas Universitarias de Valencia, Valencia, 2008.
} 
Entre esos dos polos se ha movido gran parte de la discusión sobre la relación entre las memorias (sociales, individuales, colectivas) y la historia en tanto disciplina académica. Fueron y son actitudes y programas de investigación disciplinar profundamente diferentes: crítico con las memorias y normalizador uno, autocrítico y construido sobre la noción de una relación dialéctica el otro. Por fuera de esos polos solo quedarían los abordajes más radicalmente posmodernistas -hoy ya en retiradasegún los cuales no habría diferenciación alguna entre esos discursos, ambos sujetos a la arbitrariedad del poder significante. Y es que si algo tienen en común los enfoques tan firmemente opuestos de Pierre Nora y Raphael Samuel, es la noción de que memoria e historia (o si se prefiere, historiografía) son dimensiones distintas de la producción de sentido. Sea por una clara distinción en uno, sea por una interpenetración sin confusión en otro, los historiadores realizarían una tarea metódicamente guiada, con reglas de oficio, con pautas de producción de conocimiento controladas por sus pares.

¿Qué pasa entonces cuando un/a historiador/a registra sus memorias? Tenemos multitud de ejemplos de cultores de la profesión historiográfica que por una u otra razón, en textos especialmente escritos para tal fin o en entrevistas registradas de variadas maneras, en prólogos breves o en libros extensos, han volcado sus memorias. La conciencia de sí de todo individuo y sus seguramente varias conciencias de grupo, todas siempre inestables y en permanente redefinición, se cruzan de modo inevitable con los resguardos y reflejos de uno de esos agrupamientos colectivos: la corporación académica. Cuando una historiadora o un historiador da cuenta de sus memorias, las traslada de un soporte a otro en procesos en los cuales intervienen muchos otros actores y construye una selección de los recuerdos que atraviesan su mente, lo hace con toda probabilidad sobredeterminado por las marcas de su oficio.

Tal vez Eric Hobsbawm, que marcó con sus interpretaciones la historia de lo que suele llamarse la modernidad avanzada, sea también aquí un ejemplo paradigmático de las memorias de un historiador: una autobiografía amplia tanto temporal como temáticamente, que recorre sus distintos momentos vitales pero los enlaza constantemente con aspectos de la historia político-social y con elementos de crítica cultural. Un escrito en gran medida autojustificatorio y al mismo tiempo fuertemente analítico y hasta autocrítico, en el cual el autor habla poco de sí mismo y mucho de los contextos por los que atravesó. Aunque en rigor la marca principal de memorias como las de Hobsbawm es la conciencia de la contingencia. La profesión se impone en la noción de que los estados de cosas, los procesos, los acontecimientos, podrían haber sido de un modo o de otro; que si bien los seres humanos se encuentran condicionados, sus acciones podrían haber tomado sentidos diversos de los que efectivamente ocurrieron. Esa sensibilidad ante la contingencia no supone volver inestable el pasado, en tanto que los caminos posibles en un momento se cerraron en lo que efectivamente ocurrió, sino sobre todo ser conscientes de la inestabilidad del propio presente y de la importancia de las propias decisiones en el momento mismo de la rememoración:

"El examen que debe pasar la vida de un historiador o de una historiadora consiste en ver si son capaces de plantear preguntas y responderlas, sobre todo preguntas del tipo « $i Y$ si...?», en torno a cuestiones de importancia pasional para ellos mismos y para el mundo, como si fueran periodistas que informaran de cosas sucedidas mucho tiempo atrás; y no como sujetos extraños al asunto, 
sino como quien está profundamente implicado en él. No son cuestiones sobre la historia real, que no trata de lo que pueda gustarnos o no, sino sobre lo que sucedió o pudiera haber sucedido de otro modo, pero no fue así. Son cuestiones sobre el presente, no sobre el pasado..." 6

Es posible afirmar que en esa senda de preocupaciones se inscribe un texto autobiográfico con el cual Juan Carlos Garavaglia quiso dejar testimonio de su socialización política. Tarea poco fácil, sin dudas, para quien siendo un reconocido historiador que se desempeñó en distintas universidades de América Latina y de Europa, estaba imbuido de un sentido de diferenciación entre la memoria y la historia. Sustancialmente diferente a la de modelos como el de Hobsbawm en sus formas y selección de contenidos, si bien igualmente impregnado de la conciencia de la contingencia y al tiempo de la distancia entre ese ejercicio y la labor profesional. Al decidir su escritura, Garavaglia sabía fehacientemente que no estaba produciendo un libro encuadrado en lo que se denomina historiografía, pero que tampoco era una ficción como las narrativas en las que había incursionado.

\section{2.}

Reseñar el contenido de las memorias publicadas por Juan Carlos Garavaglia parece una empresa impertinente en los múltiples sentidos de la palabra. ${ }^{7}$ No sería adecuada en tanto el comentario de este tipo de textos no puede realizarse con las reglas del oficio o los modos de reseña propios de las disciplinas académicas. De libros encuadrados en un formato académico puede presentarse una exposición sintética con cierto éxito: cuanto menos se toman las hipótesis principales, se resume el orden de los capítulos y se copian dos o tres conclusiones. Eso es imposible en el caso que nos ocupa, pues el escrito no guarda la estructura disciplinarmente consagrada y es de una índole completamente distinta. Pero además la reseña de contenido sería profundamente molesta, pues inevitablemente restringiría la riqueza de un relato polifacético y abierto, fijando la mirada en unas pocas cuestiones y acontecimientos que quien reseña considera fundamentales.

En consecuencia, este apartado y el siguiente tratan de proponer una caracterización general del libro de memorias de Juan Carlos Garavaglia y de mostrar cómo está construido, en el convencimiento de que incluso los valores de su riqueza testimonial se opacan frente al modo en el cual se escribió la obra. Probablemente sea una lectura que tras un breve inicio se aleja de los elementos de análisis de contenido -tanto de los referidos al período sobre el que versa como los correspondientes a la vida de su autor- y que por el contrario se enfoca en el cómo de una narración. Sin embargo, este ejercicio parece pertinente para apreciar la forma en

\footnotetext{
${ }^{6}$ HOBSBAWM, Eric Años interesantes. Una vida en el siglo XX, Crítica, Buenos Aires, 2003, pp. 378-379.

7 Cabe señalar que estas memorias de Garavaglia fueron profusamente comentadas en el ámbito académico y muchas veces elogiadas. Pese a ello, no conozco muchas reseñas del libro. Una de absoluta brevedad y casi apenas una noticia, es la de CAPDEVILA, Luc "Juan Carlos Garavaglia, Una juventud en los años sesenta", en Nuevo Mundo Mundos Nuevos, en línea el 10 de diciembre de 2016, http://journals.openedition.org/nuevomundo/70062, consultado en diciembre de 2017. Otra, centrada en la crítica de Garavaglia a la lucha armada y en su supuesta adhesión a una "ética burguesa", en COSTILLA, Ana "Lo pasado, pisado", en El Aromo, núm. 86, 2015, en línea en http:/ / razonyrevolucion.org/lo-pasado-pisado-ana-costilla /, consultado en diciembre de 2017.
} 
la cual un eximio historiador construyó una sistematización de sus propios recuerdos, algo de lo cual cabe aprender mucho y quizás tanto como lo que enseñó en su actividad académica. Conviene entonces comenzar por intentar una caracterización general del libro de marras. Y la afirmación inicial puede ser que Una juventud en los años sesenta es esencialmente autobiografía política, si por "política" entendemos cuestiones más amplias que las que laten tras los estudios de los sistemas electorales, los partidos políticos y los tejemanejes de las élites.

Claro está que el libro no es un recuento de todas las actividades o actitudes que su autor asumió a lo largo de su vida y que podrían calificar dentro de amplísimo universo de la política entendida como campo de las relaciones de poder, sino de un recorte relativo a su biografía: el que hace a su formación política, su adhesión al peronismo, su pertenencia a la Organización Político-Militar Montoneros y su exilio. En ese recorrido, el tono de Garavaglia no deja de ser en gran medida autojustificatorio, aunque la necesidad de dar cuenta de las opciones tomadas en momentos históricos y geografías concretas -con decisiones muchas veces erróneas, según su propio criterio-no se instala como el problema de un sujeto individual, sino de toda una generación política. Repetidamente se alude a la idea de explicar a quienes hoy son jóvenes lo que significó ser joven de una clase social, una educación y unas perspectivas políticas determinadas, cincuenta años atrás.

Cuando decidió escribir y publicar sus memorias políticas, el autor no sabía que le quedaban pocos años de vida - de hecho, su cruel enfermedad fue tan rápida como inesperada- pero estaba en un punto de inflexión. Se retiraba progresivamente de sus puestos en la École des Hautes Études en Sciences Sociales de París y de la Universitat Pompeu Fabra de Barcelona, y gracias a su contratación por el Consejo Nacional de Investigaciones Científicas y Técnicas de Argentina emprendía con Elisa Caselli una nueva etapa en la Universidad Nacional del Litoral. En ese momento de reacomodamientos surgió probablemente en él la necesidad de "dar cuenta de" -de las opciones anteriores, de las actuales, de las culpas asumidas o de las proyecciones desde el hoy hacia el pasado-, aunque lo que primó en la presentación de Una juventud en los años sesenta fue la noción de trasmisión de una experiencia. Como puede apreciarse de diversas expresiones o comentarios a lo largo del libro, la conciencia de la transitoriedad o la finitud se articulaba en él con la idea de una suerte de abismo de sentido entre las distintas generaciones. La recuperación de los recuerdos aparecía entonces como un modo de tender puentes entre una generación marcada por las experiencias de la esperanza revolucionaria y la matanza generalizada, y otras que no vivieron esas situaciones y que están formadas en mundos simbólicos completamente diferentes.

El término "experiencia", tan thompsoniano y a veces esquivo o poco claro, asume en el texto de Garavaglia una dimensión muy amplia. Atento a la multiplicidad de las situaciones posibles, a la ubicación de los actores en redes de relaciones, al hecho de que la vida social es multifacética y no se cierra en una u otra dimensión, a ver en los documentos las opciones que unas u otras personas tomaban en momentos dados, el historiador se aplicó esos mismos criterios para construir sus memorias. Notoriamente, le interesó dejar constancia no sólo de las experiencias que tuvo -de esa ingente cantidad de cosas que le suceden a la gente cuando está viva, diríamos-, sino también de las que no tuvo. En ese sentido remarcó las circunstancias por las que quedó excluido del matar o morir, del horror represivo o incluso de la limitada función de un Scholar, ya que su erudición y sus honores académicos no lo 
alejaron de las preocupaciones por hacer del mundo un lugar más amable para toda la humanidad.

En la narración de Juan Carlos Garavaglia, esas experiencias directas o vicarias supusieron constantes aprendizajes. Lo que entonces se quiere trasmitir es el depósito de sentidos, saberes e impresiones que quedaron en el sujeto que escribe, en un largo y amplio registro que va desde una niñez peregrina en el seno de una familia progresista en lo político y muy activa en lo cultural, hasta las enseñanzas del exilio o las que surgen de casuales charlas de café. La autobiografía se presenta como un modo de dar cuenta de una educación política, de la manera en la cual ésta se produce ininterrumpidamente en un entramado social determinado, marcado por pertenencias y saberes de clase, por intercambios personales y grupales, por acontecimientos o series de acontecimientos que producen alteraciones profundas en los esquemas de percepción de los sujetos. Y ante la multidimensionalidad de la vida social, las experiencias son también el punto de acercamiento y comprensión de los otros. Frente al Garavaglia memorialista se erige el mismo problema que acicateó al Garavaglia historiador: cómo comprender la vida y el sentir de las clases populares. Comenzando por la anécdota de una empleada doméstica empecinada en homenajear a la fallecida Eva Duarte de Perón y pasando por el error de cálculo de Montoneros al colocarse en oposición a un líder que era el verdadero detentador de la autoridad carismática, la educación política se presenta por sobre todas las cosas como un aprendizaje de los sentimientos populares.

Articulados con las etapas de la vida familiar, escolar, laboral y académica, esos aprendizajes vienen entrelazados con las emociones del autor, que incluyen hasta sus experiencias amorosas. Rememoración de emociones pasadas, pero también presentación de emociones del momento de la escritura -desde una de las dedicatorias iniciales "A Elisa que conoce las lágrimas escondidas en estas páginas"-Recuerdo también de instituciones, las más de las veces educativas, que son consideradas fundamentales no sólo en lo que tuvieron de importancia para una formación académica o para un contexto de luchas sociales, sino además para la formación de redes personales, la empatía con unos y el rechazo de otros. Así, la implicación de Garavaglia es total, visceral, sin que la conciencia de la diferencia entre historia y memoria impida un diálogo entre las dos: la movilización de motivos para el trabajo historiográfico se reconoce en la escritura de la memoria, mientras que ésta se cimienta en elementos que provienen de los conocimientos aportados por la historia.

El resultado general son unas memorias políticas salpicadas de emociones, de sentimientos de afecto o de indignación, según el caso. Unas memorias atípicas porque no son ni el recuento claro de las posiciones asumidas en la práctica de un activismo social o político, ni el repaso sistemático de una historia general en la cual se inserte el sujeto que escribe. Son, sí, la demostración de una larga, profunda e inacabada educación sentimental, de la cual la dimensión política es el componente esencial.

3.

¿De qué modo se escribieron esas memorias? Inicialmente, es fácil coincidir con las gacetillas de prensa y con las escasas reseñas disponibles: el eje temático de esa autobiografía política está dado por la explicación del autor respecto de su ingreso a Montoneros, su experiencia en la organización, la evaluación de sus errores y la necesidad de superar ese pasado mediante un ejercicio de reflexión equilibrado. Esto 
último no supone la idea de una "memoria completa" ni la intención de cargar culpas y repartir sambenitos por igual a cualquier actor individual y colectivo. Garavaglia sabía bien quiénes eran los muertos y quiénes los asesinos. La memoria es pensada siempre en su texto como algo ubicado en un punto focal, estrechamente vinculado a la identidad (o identificación) de quien recuerda. El reconocimiento de los errores estratégicos de las organizaciones armadas setentistas y la revalorización de la "democracia real" experimentada por primera vez en los países de acogida durante el exilio no llevaron a Garavaglia a una anulación del juicio crítico sobre el pasado argentino y latinoamericano. Frente a quienes hoy descontextualizan la violencia insurgente de los años de 1960-1970, reducen la tragedia a una caricatura y homologan todas las experiencias rebeldes o revolucionarias poniendo a jacobinos, communards, anarquistas, bolcheviques, guevaristas y piqueteros bajo un mismo paraguas, ${ }^{8}$ Una juventud en los años sesenta presenta la posibilidad de comprender esa violencia desde sus mismas fuentes y en un contexto social, político y emocional determinado.

Ese eje temático se ve interrumpido, desviado, complementado y enriquecido por múltiples acotaciones y excursos. Estrategia narrativa que como se verá tiene sus méritos y que permite reinstalar constantemente la noción de la contingencia de cada momento y de diversos futuros posibles en un pasado dado. La reiteración de algunas ideas o explicaciones hace a la continuidad de tal eje a lo largo del texto, pero es de destacar que algunas cuestiones centrales no quedan del todo claras. Por caso, siendo muy importante por la índole del libro y sus propósitos declarados, no hay una exposición completa de su paso por Montoneros. Aunque se refiera constantemente a ello y se hallan indicados varios momentos de su relación con "la Orga", no queda claro cómo fue su ingreso orgánico a la agrupación o cuáles los modos de su articulación antes de eso, ni sus posicionamientos en el conjunto de los debates y escisiones de la OPM. Finalmente, el relato de su alejamiento de la agrupación tampoco resulta muy convincente y deja la idea de una organización guerrillera de la cual podían salir fácilmente personas que tenían contactos o conocimientos que resguardar. En algunos casos la escritura muestra las lagunas de la memoria y en otras hay una asunción de los silencios.

Ese eje temático general puede estar relacionado con un eje teórico-conceptual. Es raro que en el comentario de un texto memorial podamos hablar de conceptos esenciales para las ciencias sociales como "Estado", pero es que en este caso las "categorías nativas" del autor o el punto de vista emic son compartidas o debatidas como parte de las "categorías analíticas" que hacen al punto de vista etic. De hecho, la cuestión del Estado atraviesa todo el texto. En ocasiones como simple demostración de su complejidad al rememorar situaciones o acontecimientos, en otros casos más explícitamente, aludiendo a los inconvenientes de concebir al Estado como un "aparato". ${ }^{9}$ El texto no es tan claro en la identificación de lo que sería el

\footnotetext{
${ }^{8}$ A mi entender, esa homologación de todas las violencias insurgentes se realiza en la estela de las interpretaciones de François Furet, de un modo propiamente anacrónico. Obviamente, responde también a un cierto "clima de época" en el cual la única violencia sin crítica admitida es aquella no reconocida como tal, que fundamenta la dominación espectacular del capital. Un planteo de los aspectos en debate en el caso argentino, en oposición a esas lecturas descontextualizadas y maniqueas en OBERTI, Alejandra y PITTALUGA, Roberto "Apuntes para una discusión sobre lamemoria y la política de los años 60/70 apartir de algunas intervenciones recientes", en Sociohistórica núm. 38, Universidad Nacional de La Plata, 2016.

${ }^{9}$ En ciertos pasajes, Garavaglia alude a la concepción del Estado como aparato como algo propio del marxismo, cuando en realidad sólo podría ser así en algunas variantes estructuralistas de esa amplísima tradición. Sobre el final del texto, dice sí que en su concepción "aparatista" las
} 
"aparatismo" aunque de diversos momentos podría entenderse por tal la tendencia al formalismo jerárquico o al fetichismo institucional en algunas agrupaciones político-militares. Como fuera, el autor es claro en su apelación a la necesidad de pensar el Estado como relación social y en su consideración de esa falencia como fuente de los principales errores estratégicos de las organizaciones armadas, que proponían "tomar el poder" ocupando el Estado como si este fuera un lugar o una cosa.

Si ese es el punto central de la autocrítica individual intentada por Garavaglia, no es menor advertir que su enunciación involucra a muchos otros que compartieron esa concepción. En el transcurso del libro hay un uso alternativo del "yo" y del "nosotros". Un "nosotros" variable, a veces estudiantil, a veces familiar, pero con más frecuencia generacional. Cuando son necesarias precisiones sobre posicionamientos políticos -suponiendo que ello es posible de sostener durante toda una vida, salvo que el individuo en cuestión sea un fósil impermeable a las transformaciones sociales-, el "yo" apela a un "progresismo de izquierda" que se sabe poco definido y a veces el "nosotros" se llama "izquierda peronista". Esto es todo un acontecimiento, porque es sabido que en general la definición de izquierdas y derechas al interior del peronismo es propia de quienes lo miran desde afuera, mientras que para muchas izquierdas el peronismo sólo puede pensarse como bonapartismo o cosas similares. ${ }^{10}$ Aunque Garavaglia distingue sus posiciones de las de aquellas izquierdas que de una $\mathrm{u}$ otra manera se mantuvieron alejadas del peronismo, no encuentra problema en hermanar de dos o tres modos distintos esas palabras. Eso también supone una revisión de sus propios posicionamientos durante el ciclo de movilizaciones de los años de 1960-1970 y una reconsideración de los problemas de comunicación entre distintas corrientes emancipatorias de ese período.

Tratándose de un texto memorial escrito por un historiador, debió ser inevitable que su autor se planteara la necesidad de recurrir a citas documentales. Las hay, mayormente a pie de página, pero en un número muy escueto. Garavaglia no convirtió sus memorias en un producto disciplinar, si bien consideró necesario en distintos momentos hacer una referencia más precisa a algún episodio, a una publicación, a un personaje o a una definición. Lo que late en el escrito es una suerte de polifonía limitada, ya que distintas voces se hacen presentes no bajo la forma canónica de la nota erudita sino de los comentarios del autor, que va insertando referencias en el transcurrir del relato.

Otros dos recursos son asimismo destacables: las formas de la adjetivación y la inserción de imágenes. Sobre lo primero, al menos hay que destacar que el uso de adjetivos calificativos es muy abundante. Garavaglia no duda en hablar del "periodismo basura" o de la "insensatez" de determinados actores, pero también es cierto que la mayor parte de las calificaciones negativas se aplica a sus propias acciones y pensamientos, que vistos a la distancia parecen no resistir la crítica del tiempo. En ocasiones en las cuales los calificativos remiten al accionar represivo, la

conducciones de las agrupaciones político-militares eran althusserianas sin saberlo.

${ }^{10}$ La noción de "izquierda peronista" no deja de ser conflictiva y su instalación como categoría del análisis histórico no siempre es aceptada. Es de destacar, por tanto, la inclusión de algunas corrientes peronistas en el universo de la "nueva izquierda" argentina de los años de 1960-1970 que defiende María Cristina Torti en "La nueva izquierda argentina. La cuestión del peronismo y el tema de la revolución", en TORTI, María Cristina (dir.) La nueva izquierda argentina (1955-1976), Prohistoria, Rosario, 2014. Esta opción a su vez impacta sobre la interpretación de la represión, permitiendo apreciar que el terror de Estado no se desarrolló sobre una diferenciación entre peronismo y no peronismo, sino sobre una cesura izquierda/derecha. 
adjetivación se fundamenta documental o lógicamente. Respecto de las imágenes es llamativo que casi ninguna incluya al autor. Tan sólo en dos fotos familiares se lo ve, pequeño y poco destacado en una huerta o en un grupo que sale de cabalgata. Inversamente y si hacemos abstracción de algunas pocas fotografías familiares, hay muchas imágenes que ilustran el contexto de su socialización política. La muerte es el denominador común de la selección, desde la primera que muestra a Eva Perón durante un discurso "cuando la enfermedad avanzaba de forma acelerada", hasta la última en la que se aprecia un grupo de personas frente a montones de huesos durante las exhumaciones de cuerpos no identificados "en un lugar no determinado de la provincia de Buenos Aires". El conjunto de las imágenes actúa como un subtexto que "pone en situación" las opciones y acciones de individuos y colectivos y es un contrapunto con el texto: mientras en éste aflora constantemente el Yo del autor, aquellas son como una demostración "objetiva” de lo que ocurría en la sociedad argentina.

La presencia de las fotografías refuerza uno de los elementos característicos del libro, que hace a la dedicación a definir materialidades en sentido estricto. Es decir, a hablar de las cosas, de cómo eran / son, de sus texturas, del modo en el cual estaban dispuestas en el espacio o se atravesaban en el tiempo. A tono con los estudios históricos de Garavaglia, eso supone también observar prácticas y definir quién(es) usaba(n) esas cosas, qué lugar ocupaban éstas en un proceso, en un instante, en un conflicto. Hasta los pies de foto reflejan ese interés por los objetos, como en aquella imagen en la que se muestran autobuses con las ruedas pinchadas y se explica su función como barricadas.

Por fin, el logro más evidente y excelso del texto es su manejo del tiempo. Contra la idea de una biografía que avanzaría de etapa en etapa en sentido progresivo, la escritura del libro va y viene en el tiempo. No es el fluir de la conciencia ni el abigarramiento de los recuerdos o su superposición; tampoco el anacronismo o el emparejamiento sin sentido. Es una verdadera articulación de los tiempos lograda mediante una narración compleja, abierta, que va construyendo espacios para la digresión al tiempo que deja hilos temporales tendidos hacia adelante.

Es dudoso que Juan Carlos Garavaglia sea reconocido como un eximio literato, a un nivel equiparable al de su trabajo historiográfico. Pero su sentido de la temporalidad y de la articulación de los acontecimientos y pensamientos impresiona por su capacidad para trasmitir sentimientos viscerales. Hay una cierta maestría en la forma en la que se pasa de un elemento al otro del relato. Quizás se pueda decir que es una redacción amena; preferentemente deberíamos hablar de una asombrosa vinculación de aspectos completamente diversos. Es más, quizás la capacidad para llevar un conjunto de hilos narrativos por entre horrores, afectos, vivencias y notas de color sea lo que le da al texto la posibilidad de romper con el tiempo progresivo y monótono de los desarrollos históricos canonizados. Menos de dos páginas separan su recuerdo de Silvio Frondizi como docente y el brutal asesinato de éste por la Triple A años después, de la rememoración de su primer encuentro sexual, el carácter de idishe mame de su progenitora y la identificación de la rama tunecina de su familia hacia 1870. Y todo ello sin que el lector sienta que hay el más mínimo forzamiento y por el contrario pueda abandonarse confiado al continuum de la palabra impresa.

Aunque nunca la practicó y era ajeno a los debates sobre sus formas y definiciones, Garavaglia asumió en sus memorias una de las características definitorias de la Historia del Presente: la capacidad para evadirse de cuán recientes 
o lejanos sean los procesos o acontecimientos sobre los que se trate, siempre que puedan ser comprendidos como parte de un presente actualmente significativo.

\section{4.}

Probablemente Una juventud en los años sesenta requiera críticas más rigurosas y detalladas, que recorran su contenido y lo reconstruyan de modo sistemático. Tal vez deba emprenderse su análisis en función de nuestro conocimiento sobre la Historia Reciente argentina y latinoamericana, o por el contrario ese camino resulte vano, pues como expresión de una memoria situada el libro no pueda dar cuenta más que de las propias emociones y evocaciones de su autor.

¿Qué es lo que el libro de memorias políticas de Juan Carlos Garavaglia nos ha dejado? O mejor, ¿qué creía realmente él que dejaría al escribirlo y publicarlo? El malogrado Jorge Gelman -fallecido también en este annushorribilis de 2017 que ha culminado en Argentina con una brutal transferencia de ingresos a favor de los más poderosos- escribió para la contratapa que "...pese a no ser un libro de historia nos mete en ella y nos deja mucho para pensar sobre el pasado reciente de este país y sobre su presente". Es casi imposible no coincidir con esa frase, aun para quienes denosten las opciones finales de Garavaglia o su mirada sobre ese pasado de conflictos en el que vivió.

En el ejemplar que tengo en casa hay una dedicatoria del 21 de septiembre de 2015 de puño y letra de Juan Carlos, para mi pareja María Laura Tornay y para mí. En un punto sus palabras rezan "¿Qué decirles que ustedes no sepan?". Debo confesar que cavilé muchas veces sobre el significado de esa frase interrogativa. ¿Qué era lo que sabíamos o sabemos? ¿Lo que refiere a la historia de las luchas sociales de las décadas de 1960-1970? ¿La deriva de la Organización Político-Militar Montoneros? ¿La experiencia de la represión abatida sobre nuestras familias? ¿Lo que podía decirnos en el presente en tanto personas que manteníamos un vínculo afectivo con él y con su pareja? Es ahí donde la expresión de Gelman adquiere toda su intensidad: quizás Una juventud en los años sesenta no nos dé muchos más conocimientos que los que ya tenemos, pero pese a ello nos incita a pensar sobre una multitud de cosas que hacen a nuestra historia presente. Es en ese lugar de roce entre la historia y la memoria donde puede producirse la reflexión, no en su separación tajante ni en la renegación de una u otra.

Al llegar a este punto, noto también que al hablar de las memorias de Juan Carlos Garavaglia he alternado el uso de distintos tiempos verbales. Así, unas expresiones o párrafos están en alguna de las formas del pasado y otras en presente. Lo habitual en el oficio es repasar el texto y uniformizar el tiempo, encorsetarlo en una conjugación correcta -para los historiadores tradicionales, cualquiera sea esa tradición, probablemente en pretérito perfecto y pluscuamperfecto-. ausentes.

Prefiero dejarlo así. En esa pluralidad de tiempos se cuela la presencia de los

Santa Fe, diciembre de 2017. 